\title{
EL FOGÓN ABIERTO DE TRES PIEDRAS EN LA PENÍNSULA DE YUCATÁN: TRADICIÓN Y TRANSFERENCIA TECNOLÓGICA
}

\author{
Joaquín Quiroz Carranza \\ cenciart@yahoo.com \\ Universidad Tecnológica de Querétaro \\ Citlalli Cantú Gutiérrez \\ citlallicg@yahoo.com \\ Asociación Red Verde, AC
}

\section{RESUMEN}

En México, y particularmente en la península de Yucatán, el uso del fogón abierto de tres piedras y de leña combustible es un recurso de gran importancia por su cantidad de usuarios, el sustento histórico-cultural y su significado dentro del complejo de tecnologías tradicionales. Su existencia actual representa un proceso de autonomía de las poblaciones indígenas, campesinas y pobres respecto a las redes hegemónicas de energéticos convencionales. En este artículo se describen las características del fogón abierto y de las especies preferidas como leña con base en observaciones realizadas en 4,000 viviendas de 39 localidades de Yucatán y Quintana Roo, México. Se analiza el proceso de transferencia tecnológica y se describe un proceso de entrega de fogones del gobierno federal en Yucatán, interpretándose como una política de subsidio de carbono hacia la industria capitalista local y como una forma de neutralizar lo autónomo tradicional y los esfuerzos de la sociedad civil organizada por impulsar el desarrollo participativo y comunitario.

Palabras clave: fogón, leña combustible, Yucatán, Quintana Roo. 


\section{ABSTRACT}

In Mexico and particularly on the Yucatan peninsula, the use of the three-stone open fire cook stove and fire wood fuel is a phenomenon of great importance due to the number of people using it, its historical-cultural background and its meaning within the complex of traditional technologies. Its current existence represents a process of autonomy of the indigenous, peasant and poor populations with respect to the hegemonic networks of conventional sources of energy. Based on observations of 4000 households in 39 locations in Yucatan and Quintana Roo, Mexico, this article describes the characteristics of the open fire cook stove as well as the preferred types of firewood. It analyzes the transfer of technology and describes the process of delivery of open fire cook stoves by the federal government in Yucatan, interpreting it as a carbon subsidy policy for both local capitalist industry and developed countries, and as a way of neutralizing traditional autonomy and the efforts of organized civil society to promote participatory and community development.

Key words: open fire cook stoves, firewood fuel, Yucatan, Quintana Roo. 


\section{INTRODUCCIÓN}

En México, la población usuaria de leña asciende a 28 millones de habitantes, de los cuales 18 millones se encuentran en las zonas rurales y 10 millones en áreas urbanas, periurbanas y marginadas (Díaz 2000: 1-5, Masera y Fuentes 2006: 1-10, Quiroz et al. 2009: 20, y Quiroz y Orellana 2010: 47-67). En la península de Yucatán, más de un millón de habitantes usan leña como combustible fundamental en la vivienda o de forma mixta con gas LP (INEGI 2000).

La leña es el combustible fundamental de los habitantes de las zonas marginadas de México. Su uso y manejo a escala doméstica implica un conjunto de valoraciones y conocimientos tradicionales, los cuales conforman un sistema que les permite satisfacer necesidades y generar bienestar a los integrantes de la familia.

La leña se consume a través de un fogón abierto de tres piedras o uno tradicional en forma de U. La selección de las piedras y de las especies leñosas involucra un vasto conocimiento empírico y tradicional de los usuarios, quienes reconocen las características físicas de las piedras y químicas de la leña sin describirlas formalmente. Por ejemplo, para su uso en el fogón prefieren piedras duras o lajas, así como leña proveniente de especies vegetales que al arder genera poco humo, su combustión es lenta y produce brasas.

La importancia de la leña radica en que puede colectarse de forma directa, lo que evita un gasto monetario, su transporte depende fundamentalmente de energía humana y animal, puede ser almacenada largo tiempo y se encuentra disponible en el entorno inmediato. Estas características permiten definirla como un combustible local y autónomo ya que no depende de las fuerzas del mercado, no está vinculado a las redes hegemónicas y dominantes de los energéticos nacionales o internacionales (CFE, PEMEX o petroleras transnacionales) y posee gran importancia cultural e histórica. 
Derivados de los convenios internacionales en materia de disminución de emisiones de carbono a la atmósfera, en México se han implementado programas que pretenden justificar la aportación gubernamental en la materia, uno de los cuales es el Programa Nacional de Estufas Ahorradoras de Leña (PNEAL).

En este artículo se describe el fogón abierto de tres piedras, el aprovechamiento de la leña y las tendencias de transferencia y adopción tecnológica. Las observaciones se realizaron en 4,000 viviendas de 39 localidades de Yucatán y Quintana Roo entre los años 2005 y 2010. Los resultados evidencian una amplia distribución y uso del fogón abierto de tres piedras, así como el aprovechamiento de una gran diversidad de especies vegetales leñosas como combustible doméstico. De igual forma, se muestra que el fogón de tres piedras es una tecnología tradicional que los usuarios modifican de acuerdo a sus posibilidades y necesidades. Por otra parte se revisa el soporte histórico-cultural del fogón y la leña, y lo que implicaría su extinción para el conglomerado cultural y económico de la región peninsular. Finalmente, se analiza el proceso de transferencia tecnológica derivado de la realización de programas gubernamentales de distribución de fogones eficientes y su impacto en las comunidades usuarias del fogón tradicional.

\section{ANTECEDENTES}

La vivienda maya está inserta dentro de un microterritorio denominado tankaab o solar. El área residencial es el centro del kaajo, comunidad, acepción que trasciende este concepto, pues kaaj no sólo representa la base material que une a un conglomerado humano, sino también otros aspectos, como lo señalan en Kancabchén, Quintana Roo: «lo que nos identifica, el trabajo colectivo recíproco, la casa grande, las ceremonias y rituales» (comunicación personal de Yuli Yam Uh, 2009), actividades cuyo centro es el fogón de tres piedras.

El tankaab o solar tiene dos espacios, el abierto o traspatio y el cerrado o vivienda. En esta 
última generalmente el mobiliario es simple: hamacas, sillas y una o dos mesas de madera, pero resaltan dos subsistemas fundamentales: «el altar o mesa santa y el fogón» (comunicación personal de don Tula, h'meno, curandero tradicional de Peto, Yucatán, 2009). «El primero constituye el símbolo prominente de la actividad ritual, el segundo es el punto de fusión espacio temporal que representa la exaltación de la vida y está relacionado con el antiguo culto al fuego que presidía numerosas ceremonias domésticas» (Oliver et al. 2003: 103-142). En la cosmovisión mesoamericana, el fuego es el ancestro de todo el universo conocido.

Para los nahuas, el fogón de tres piedras representaba a los tres guardianes del fuego: Mixcóatl, Tozpan e Ihuitl. En Xochimilco, Chantico era la patrona del fuego (Manjarrez y Montaño 2010: 43-44). Entre los mayas, el fogón, ok’óoben, formado por las tres piedras, simbolizaba la cualidad femenina (Hirose 2007: 1-31). De acuerdo con Guzmán (2007: 101-120), el fogón preserva el fuego vital que mantiene unidos a los tres planos del mundo, simbolizados por una piedra cada uno. Allí la mujer ayuda al sol a renacer, a regenerarse todos los días tras su viaje por lo oscuro.

El solar o tankaab es el lugar de las decisiones femeninas y la cocina constituye el punto más importante de reunión familiar, donde el fogón de tres piedras es el núcleo fundamental.

Según Bernardino de Sahagún, citado por Long (2008: 127-136), la mujer era considerada en la época prehispánica «el centro y el calor del hogar» y «cuando nacía una niña, enterraban su cordón umbilical debajo del metate o cerca del fogón, para que ella se sintiera arraigada a la cocina». Esta práctica cultural aún se realiza en diversas localidades y regiones de Mesoamérica. Según don Natalio (h'men o curandero tradicional de Kinchil, Yucatán, 2006), en diversas localidades de los municipios de Hunucmá, Tetiz y Kinchil, Yucatán, se nombra esa práctica como «la quema del tuch»y consiste en incinerar el cordón umbilical del recién nacido como parte del ritual que da paso de una etapa de vida a 
otra.

En la visión hegemónica capitalista actual, el fogón de tres piedras y el uso de la leña combustible en la vivienda indígena y campesina, se observan como imágenes de atraso cultural, fuente de contaminación ambiental y un sistema que impacta negativamente las selvas y bosques (Semarnat 2008: 7-22); se desprecia como pilar de la necia idiosincrasia de nuestros pueblos y, por ello, las políticas públicas buscan extinguirlo como núcleo cultural del ser autónomo, de resistencia cultural e histórica, como esencia de la cosmovisión indígena y espacio de poder del género femenino. La erosión o destrucción cultural que significa la erradicación exógena del fogón tradicional y del uso autónomo de la leña, se justifica con argumentos pseudocientíficos sobre la contribución de la combustión de biomasa a las emisiones globales de dióxido de carbono $\left(\mathrm{CO}_{2}\right)$, principal gas de efecto invernadero. En este sentido, es muy común que organismos económicos internacionales definan como un binomio inseparable la pobreza y la degradación ambiental (Martínez 1991: 55-73).

Al respecto, y de acuerdo con INE-Semarnat (1999: 3), en México las emisiones de $\mathrm{CO}_{2}$ derivadas de la combustión de energéticos residenciales y comerciales alcanzaron el 5.3\% en 1990 y a escala mundial la combustión de leña no supera el 4\% de las emisiones globales de este gas de efecto invernadero (Ghilardi et al. 2007: 475-491). De igual forma, se considera que la combustión de leña y otros combustibles derivados de biomasa no produce dióxido de carbono neto porque este proceso libera la misma cantidad de $\mathrm{CO}_{2}$ que absorbe la biota terrestre y marina mediante los procesos fotosintéticos (Leggett 1990: 480501).

El uso de leña como combustible doméstico incluye diversos aspectos ambientales y sociales entre los que destacan: 1) la satisfacción de los requerimientos de energía doméstica de una amplia población rural y urbana marginada; 2) la perturbación de las comunidades vegetales, con repercusiones en la flora y fauna asociada, cuando se supera la 
capacidad de recuperación del ecosistema, sobre todo cuando la leña se incorpora al sistema comercial dominante mediante su uso en empresas comerciales o industriales; y 3) el impacto social, económico y de salud sobre los integrantes de la familia derivados de los procesos de acopio, transporte y combustión ineficiente (Masera y Fuentes 2006: 1-6, Díaz 2000: 1-5 y Ghilardi et al. 2007: 475-491).

Los patrones de consumo de leña en las localidades rurales o urbanas marginadas se modifican de acuerdo a las condiciones ambientales, hábitos, costumbres, tradiciones, implementos usados y tamaño de la familia, entre otros. El uso y manejo doméstico de leña es un proceso fundamentalmente de autoconsumo del cual se encargan las mujeres y los niños, en las proximidades de la vivienda, y el hombre de forma conjunta con sus labores agrícolas (De Montalebert y Clément, 1983).

El proceso originario de generación, transferencia, apropiación e innovación social de la tecnología le permitía, al productor, la utilización creativa de sus capacidades de observación y raciocinio (Samir 1977: 198-205). Algunos ejemplos de técnicas y tecnologías locales de la época prehispánica mesoamericana son el molcajete, el metate, el brasero, las flechas, el arco, los arpones y anzuelos, las herramientas para labrado de madera y piedra, las mezclas cementantes, las sogas y cordeles, el fogón doméstico de tres piedras y la obtención de tintes naturales, entre muchos otros.

En la actualidad, con el acelerado proceso de concentración del conocimiento científico, técnico y tecnológico en los polos hegemónicos capitalistas, las regiones subdesarrolladas, marginadas y empobrecidas se miran, desde la óptica de los teóricos del desarrollismo y de los estados asistencialistas, como nichos a los que hay que transferir tecnología para promover su «desarrollo», esto bajo la consideración de que siempre y en todo momento la racionalidad tecnológica sea orientada por el control jerárquico, el poder y la utilidad económica (Fuentes 2009: 346-361). En este sentido, se entiende que una sociedad tradicional se ha modernizado cuando el modo de producción campesino pasa al modo 
agroindustrial (Damián et al. 2007: 36-55).

En todos los ámbitos de la vida humana, la tecnología y la técnica permiten potenciar las capacidades de producción material y de reproducción social, favoreciendo el bienestar y la autonomía y generando capacidades creativas, así como la utilización y el fortalecimiento de los propios conocimientos (Berrueta y Limón 2008: 113-129), lo que significa la recuperación y fortalecimiento del poder local y las capacidades de gestión. Esta situación ha sido revertida y/o minimizada por los procesos de globalización colonial, neocolonial y capitalista desde hace 500 años, cuya tendencia es a la centralización jerárquica.

La dominación tecnológica se da en diversas escalas. Por una parte está la dependencia de los Estados nacionales subdesarrollados respecto a las metrópolis imperialistas, y por otra, de las comunidades rurales respecto a las instituciones gubernamentales. En México, la generación y transferencia de tecnología es realizada, por decreto (Tapia 2002: 179-183, Damian et al. 2007: 36-55), desde los polos de desarrollo tecnocientífico, es decir, desde los centros de investigación científica o instituciones de educación superior estatales o privadas, hacia las comunidades marginadas. El objetivo de este proceso es promover el «desarrollo» desde arriba hacia abajo y desde fuera hacia dentro.

El modelo hegemónico de generación y transferencia de tecnología presenta básicamente los siguientes elementos: a) no se toma en cuenta la diversidad de productores o condiciones de vida de los potenciales beneficiarios; b) se considera que el desarrollo, la producción y reproducción social, sólo se puede lograr por el uso indiscriminado de un modelo científico y tecnológico centralizado; y c) la investigación incluye cuatro fases: experimentación, validación, difusión y adopción (Damian et al. 2007: 36-55), las tres primeras bajo control central y la cuarta de aplicación local.

En términos generales, el cambio tecnológico implica: a) un proceso continuo de observación, registro y experimentación, es decir, de investigación; b) un conjunto de 
actividades que posibilitan la entrega y recepción de las innovaciones, la transferencia; y c) la valoración y uso, es decir, la adopción (Berrueta y Limón 2008: 113-129). Este proceso puede darse desde la perspectiva jerárquica a través de rígidas cadenas de mando o mediante interacciones heterárquicas, es decir, sin un mando central, como se hace en algunos procesos tradicionales indígenas y campesinos.

En el ámbito rural la generación, transferencia, adopción e innovación de tecnología es un proceso continuo y recurrente, directo e indirecto, que se practica desde la infancia. Ejemplos de esto son los juguetes y juegos tradicionales, el granero y sus técnicas de conservación de las cosechas, los aperos de cacería y el fogón de tres piedras, entre muchos otros.

Respecto a los fogones, en los últimos 50 años se han desarrollado en México una serie de modelos eficientes como son las estufas Lorena y Patsari (Troncoso et al. 2007: 27992810), el fogón sin humo, el Cheranatzicurín (Dutt et al. 1989: 43-47), la Chanti y Tuúmbenk'óoben, diseñadas, probadas, construidas y difundidas bajo concepciones diversas. Particularmente los modelos Patsari, Cheranatzícurin y Tuúmbenk'óoben siguieron procedimientos participativos, no así la Chanti, fabricada masivamente por la empresa Mexalit S. A. de C. V.

Las iniciativas de la sociedad civil y de los científicos comprometidos con el desarrollo endógeno se han visto vulneradas por las aplicaciones equivocadas de las políticas federal y estatales, pues, derivado de los compromisos ambientales internacionales y de la falacia de combate a la pobreza extrema, que en realidad es una política de contrainsurgencia (Zibechi 2010: 155), los políticos de las dos últimas administraciones federales se han apresurado a transferir, con cierta masividad, diversos modelos de fogones eficientes. Sin embargo, estos procesos adolecen de taras sistémicas, pues sus coordenadas son de arriba hacia abajo y de fuera hacia dentro, lo que conlleva procesos donde la población local no participa siendo receptora pasiva de «trastos» cuya calidad es dudosa. 


\section{MATERIALES Y MÉTODOS}

El proceso de investigación siguió tres momentos. Inicialmente se realizó una revisión bibliográfica sobre el tema del uso y manejo de la leña en la región sureste, particularmente en los estados de Yucatán y Quintana Roo, lo que permitió detectar la importancia del tema y la poca documentación al respecto. Posteriormente se procedió a realizar trabajo de campo para observar el uso del fogón abierto de tres piedras y el consumo de leña combustible, por lo que durante el periodo de realización del estudio se visitaron 4,000 viviendas en 39 localidades de Yucatán y Quintana Roo. En la primera etapa se visitaron 1,153 viviendas de seis localidades en la región noreste de Yucatán (Caucel, Mérida; Ucú, Hunucmá, Tetiz, Kinchil y Celestún); posteriormente, siguiendo el procedimiento de transferencia de fogones eficientes de Sedesol en Yucatán 2009-2010, se visitaron 2,457 viviendas de 28 localidades en diez municipios (Cantamayec, Chapab, Maní, Mayapán, Timucuy, Tepakán, Xocchel, Chacsinkin, Tahdziú y Tetíz); finalmente se visitaron 390 viviendas en la zona norte y centro de Quintana Roo (José María Morelos y Felipe Carrillo Puerto) en el 2010.

En las zonas de estudio se realizaron observaciones directas, entrevistas informales y registros fotográficos con el objetivo de conocer las características de los fogones, la preferencia de las especies leñosas y las prácticas relacionadas con el fogón abierto de tres piedras. Además se realizaron procesos de intervención en organizaciones formales o informales de la sociedad civil y se participó en procesos de construcción de estufas Patsari.

\section{RESULTADOS}

DESCRIPCIÓN DEL FOGÓN ABIERTO DE TRES PIEDRAS Y DEL USO DE LA LEÑA EN LA VIVIENDA RURAL

Cuando un habitante de zona urbana o metropolitana enciende su estufa eléctrica, de gas LP, o su calentador de agua, no se imagina el procedimiento que realizan cotidianamente 
millones de mujeres de las áreas urbanas marginadas y zonas rurales para disponer de una fuente de calor que les permita cocinar, calentar el agua de baño o transformar un material.

La vida rural es contrastante porque allí se mezclan los servicios de la modernidad con prácticas locales. De esta forma, se usa la telefonía celular y se realiza el fecalismo al aire libre; se utilizan transportes automotores y se cocina en fogones de tres piedras; se disfruta de televisión y se habitan casas con piso de tierra; se tiene acceso a Internet y las paredes y techos de las viviendas son de materiales no duraderos como láminas de cartón, huano y bajareque. Se prefiere la ropa de marca comercial, aunque sea de imitación, pero los niños andan descalzos. Son estas áreas un auténtico modelo de la economía del subdesarrollo, es decir, de un desarrollo deformado y dependiente (fotografías 1, 2, 3 y 4).

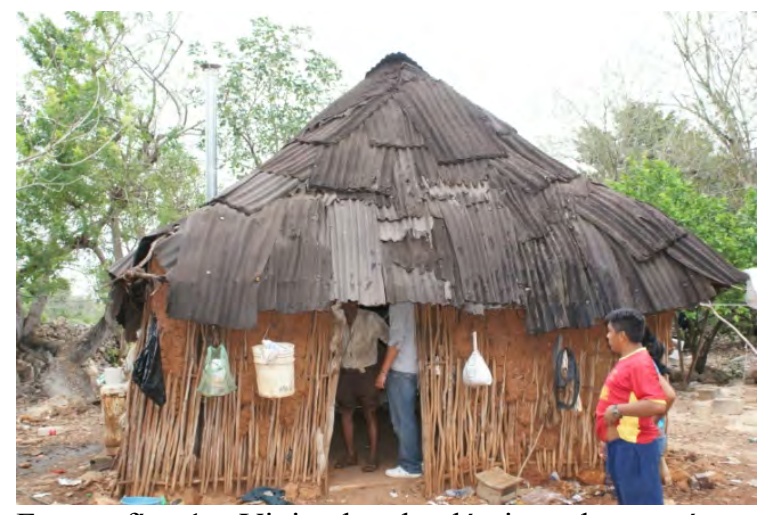

Fotografía 1. Vivienda de lámina de cartón y bajareque en Tetíz, Yucatán. (Pablo Quiroz Cantú)

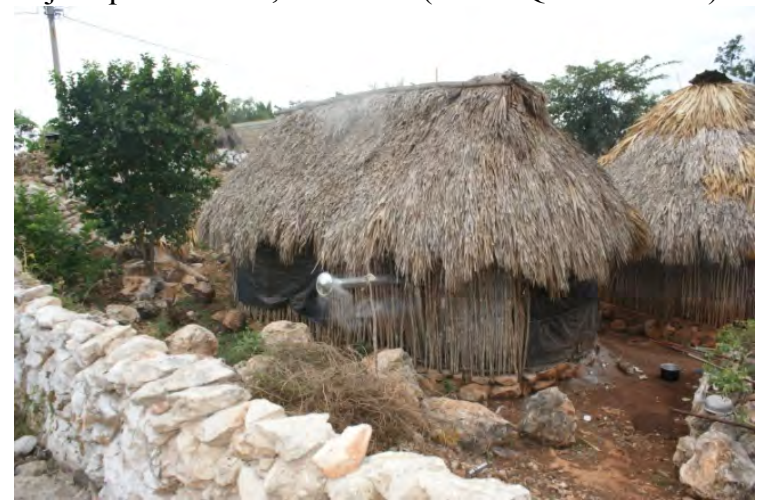

Fotografía 3. Vivienda de huano y bajareque en Tahdziu, Yucatán. (Pablo Quiroz Cantú)

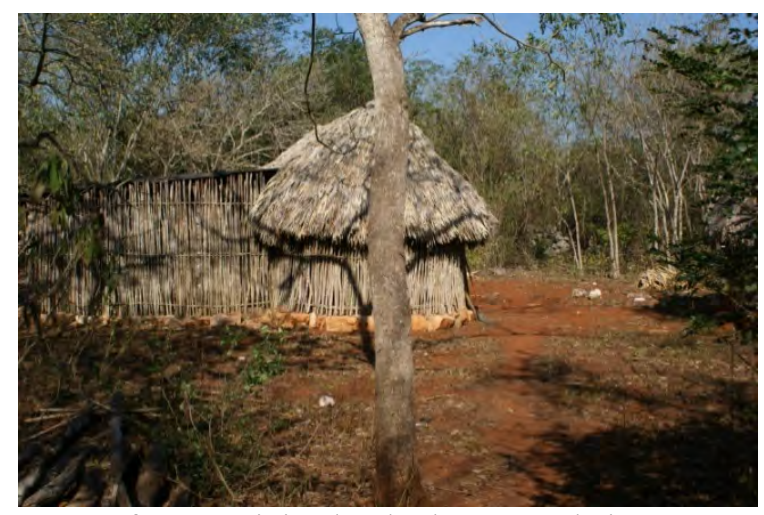

Fotografía 2. Vivienda de huano y bajareque en Pambijib, Tahdziu, Yucatán. (Pablo Quiroz Cantú)

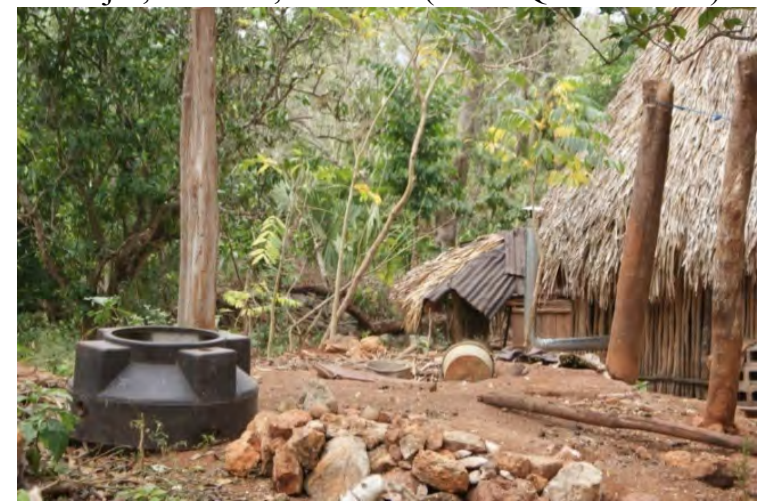

Fotografía 4. Vivienda de lámina de cartón, huano y bajareque en Tahdziu, Yucatán. (Pablo Quiroz Cantú) 
En una vivienda tradicional de las zonas rurales de Yucatán y Quintana Roo, generalmente el área de cocina se encuentra separada del espacio de uso común (dormitorio, sala y área de almacenamiento). A ella, la mujer acude desde muy temprano para reencender el fogón a partir de las brasas que se generaron el día anterior. El fogón, tecnología tradicional, está constituido por tres piedras colocadas sobre el piso y arriba de éstas se colocan ollas y tinas sobre un comal grande o parrilla (fotografías 5, 6, 7 y 8).

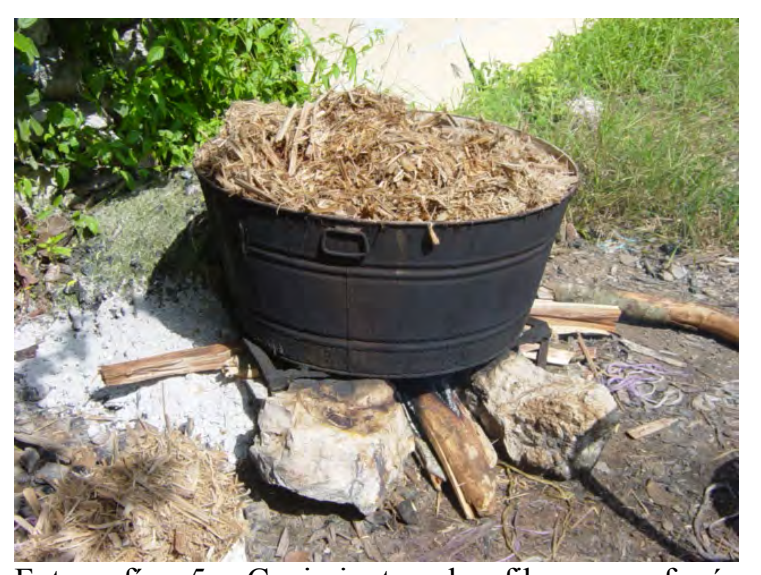

Fotografía 5. Cocimiento de fibra en fogón tradicional en Tetíz, Yucatán. (Pablo Quiroz Cantú)

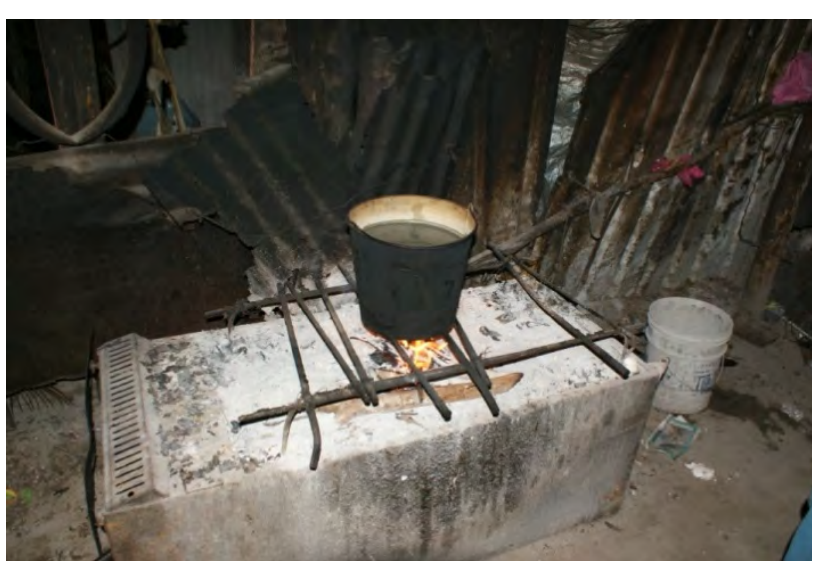

Fotografía 6. Fogón sobre refrigerador desechado en Chuburná Puerto, Yucatán. (Pablo Quiroz Cantú)

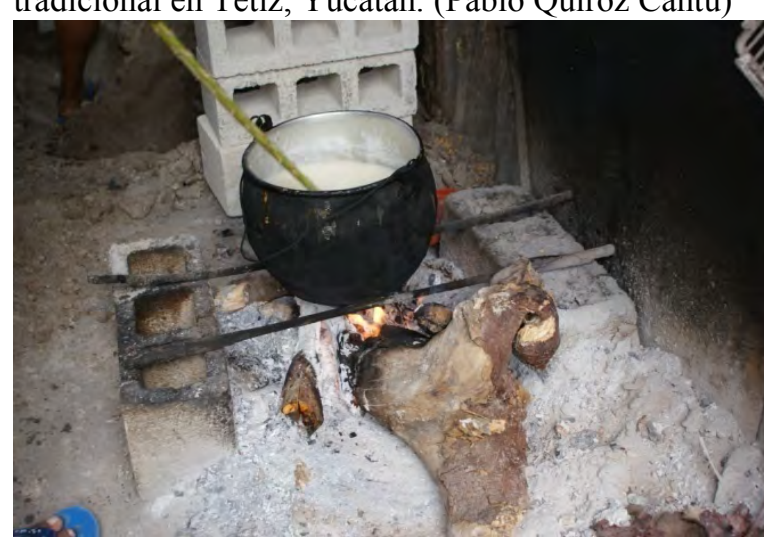

Fotografía 7. Fogón con bloques de concreto y varillas, en Chuburná Puerto, Yucatán. (Pablo Quiroz Cantú)

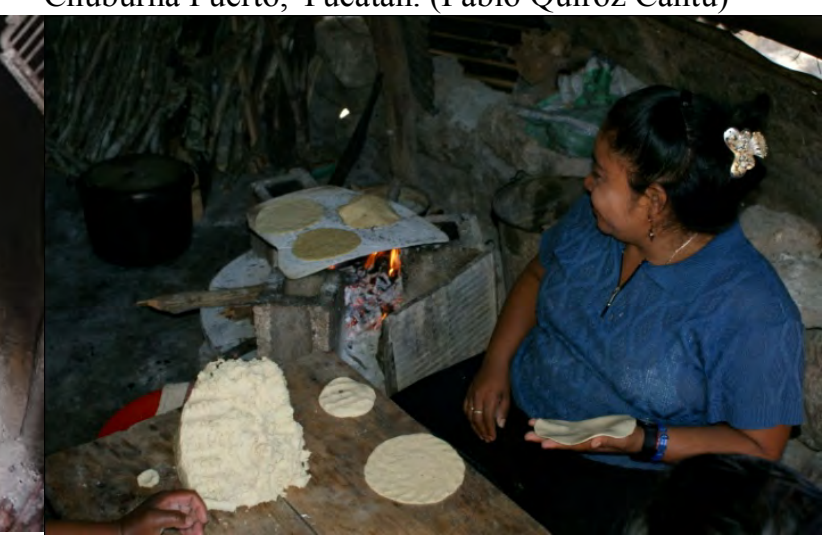

Fotografía 8. Mujer elaborando tortillas sobre fogón de bloques de concreto en Tipikal, Maní, Yucatán. (Pablo Quiroz Cantú)

El fogón abierto de tres piedras es una tecnología antigua ampliamente difundida en las culturas prehispánicas. En el altiplano mexicano se denominaba tlecuilli y en la región maya k'óoben. Está compuesto de tres piedras duras redondeadas o rectangulares, puestas 
en forma de círculo, que se colocan a nivel del suelo o sobre una plataforma de piedra, aunque puede haber modificaciones de carácter local de acuerdo a las necesidades y posibilidades de los usuarios (fotografías $9,10,11$ y 12).

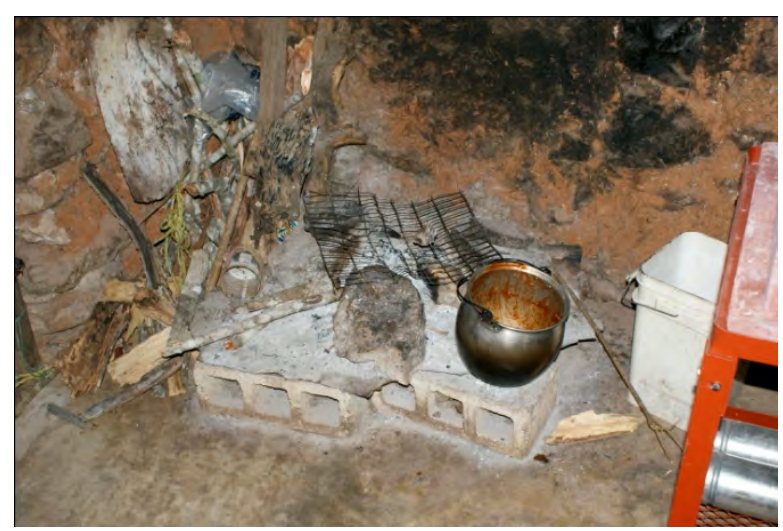

Fotografía 9. Uso de bloques de concreto y parrilla reutilizada en el fogón. (Pablo Quiroz Cantú)

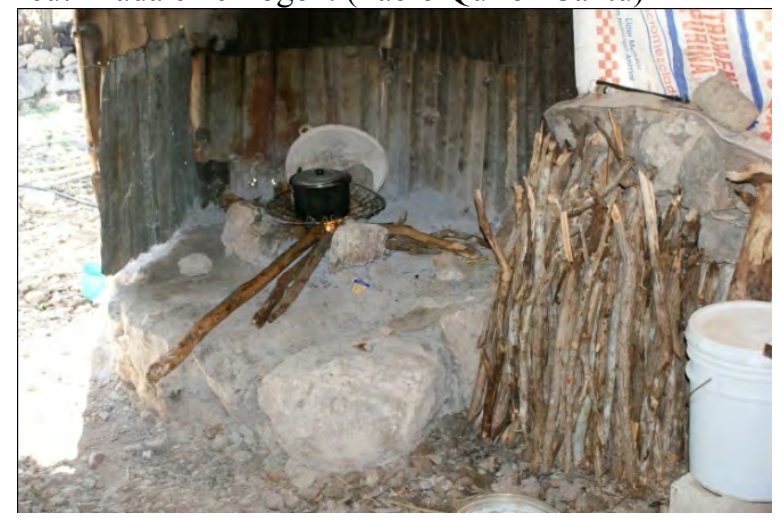

Fotografía 11. Cubierta de ventilador a manera de parrilla. (Pablo Quiroz Cantú)

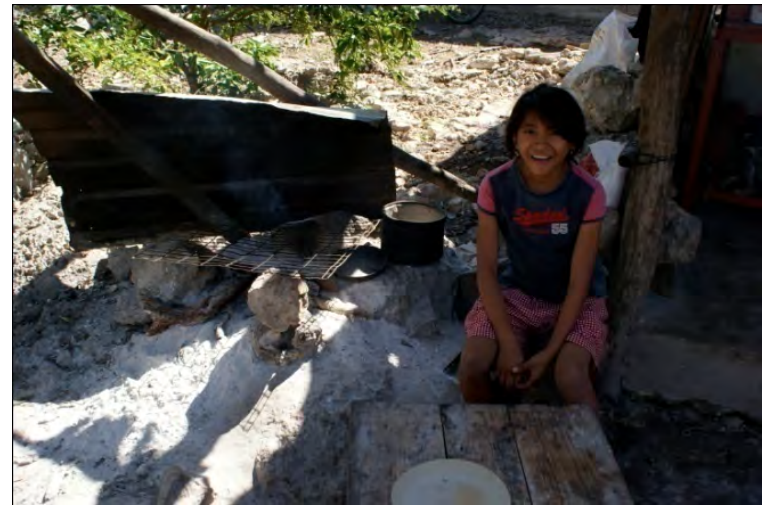

Fotografía 10. Lámina metálica aplicada para reducir incidencia de viento. (Pablo Quiroz Cantú)

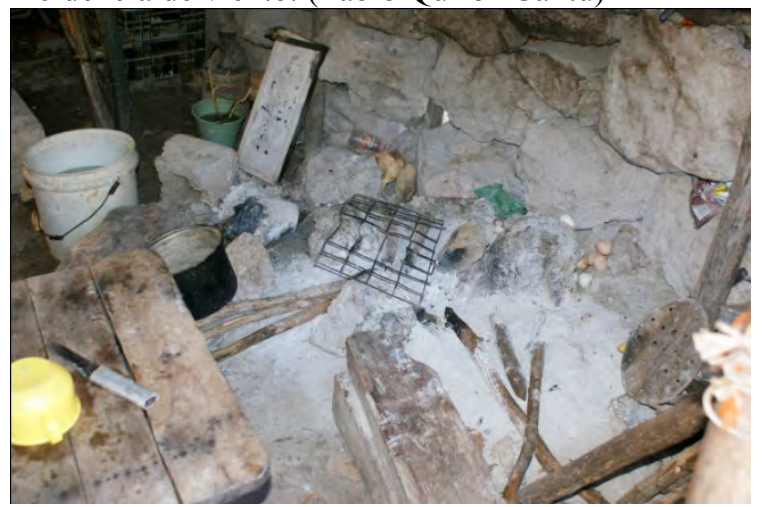

Fotografía 12. Tapa de tambo metálico perforado (esquina derecha inferior). (Pablo Quiroz Cantú)

El fogón tradicional puede encontrarse funcionando con tres piedras o éstas pueden sustituirse por tres bloques de concreto. Se observa a nivel del piso o sobre una base de 30 a $60 \mathrm{~cm}$ de altura elaborada con piedras o bloques. Asimismo, los implementos de soporte de ollas y sartenes pueden ser: la cubierta del ventilador o abanico, rejillas o parrillas residuales, láminas, varillas y alambrón, porta macetas y tapas de tambores metálicos, entre otros.

Para apreciar el proceso cotidiano de manejo del fogón y de los materiales combustibles 
derivados de biomasa, es necesario remontarse a los días previos, durante los cuales la familia se aplica en la colecta de la leña y otros materiales como cáscaras de coco, bakales u olotes, y en algunos lugares hasta desechos como papel, cartón y plásticos residuales.

El fogón tradicional, sin los artilugios de encendido de los artefactos modernos, es reencendido por la mujer cada mañana y deberá mantenerlo así a lo largo del día y durante la noche en forma de brasas, según sea la cantidad de integrantes de la familia, el tipo de comida y la cantidad de agua a calentar. En México, el promedio de consumo de leña oscila entre 2 y $3 \mathrm{~kg}$ por persona por día (Díaz 2000: 1-5, Masera y Fuentes 2006: 9-12).

En promedio, una familia rural en el área peninsular está compuesta por seis integrantes (INEGI 2000). Un núcleo familiar de estas dimensiones usa entre tres y seis rollos de leña cada semana, esto es, de 300 a $550 \mathrm{~kg}$ de leña por mes. Si la leña es adquirida por la familia, cada rollo cuesta entre seis y veinte pesos, dependiendo de la abundancia o escasez de leña en la localidad (Quiroz et al. 2009: 20, y Quiroz y Orellana 2010: 47-67). De esta forma, un rollo de leña puede adquirirse en seis pesos en la localidad de Tetiz, mientras que en Chabihau y Dzilam de Bravo se comercializa en veinte pesos.

Preparar alimentos en un fogón tradicional implica la colecta de la leña, su traslado a la vivienda, su almacenamiento y cuidado, y su corte o trozado, actividades que implican que las familias dediquen entre uno y dos días a la semana a la colecta de leña, además de la colecta que se hace a la par de «otros quehaceres, como ir a la milpa, el mercado o cualquier otra» (comunicación personal doña Juanita, Chuburná Puerto, Yucatán, 2008) y la inversión de una gran cantidad de energía humana, ya que el 70\% de los usuarios trasladan la leña en triciclos, el $12 \%$ sobre la espalda, el $5 \%$ en bicicleta y el $13 \%$ en vehículo automotor o animales de carga.

Asimismo, la vivienda y sus habitantes se someten al humo derivado de la combustión de la leña, que deja una cubierta de hollín en las paredes, techos y otras estructuras de la 
vivienda, oscurece ollas, y expone continua y recurrentemente a los integrantes de la familia a efectos negativos. El impacto del humo se manifiesta a largo plazo en enfermedades oculares o de las vías respiratorias, como son «cataratas o carnosidades de los ojos, tos y ardor de la garganta muy seguido» (comunicación personal don Lauro, Ucú, Yucatán, 2007).

Con la modificación del artículo 27 constitucional en la década de los noventa, todo lo descrito se hace más difícil debido a la privatización de la tierra social, que es entregada a nuevos latifundistas y terratenientes provocando que el patrimonio natural de los pueblos indígenas y campesinos se convierta en infraestructura capitalista - turística, carretera, fraccionamientos de viviendas unifamiliares, industrias, empresas agropecuarias o áreas de recreo para la alta burguesía - reduciendo así el acceso de la población local a las fuentes de abasto de leña. Algunos actores sociales han instalado letreros en los caminos señalando «Prohibido cortar leña, es propiedad federal, No te arriesgues» (aviso en la carretera TiculMérida, foto 13), con la intención de reducir el acceso de la población a las fuentes de abasto de leña.

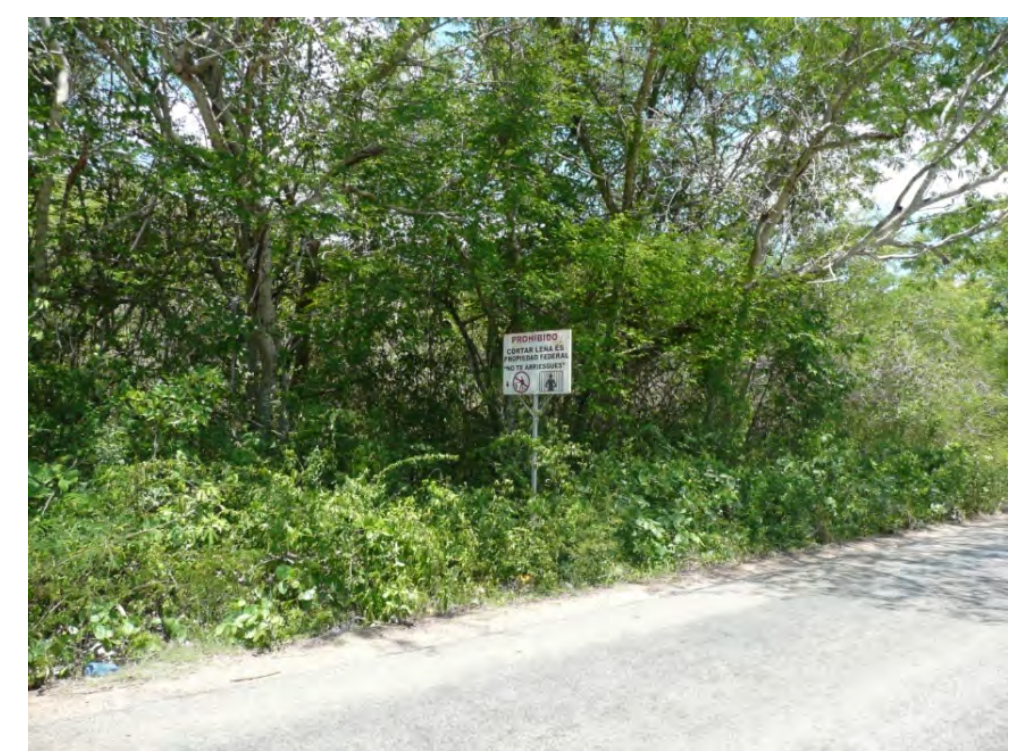

Fotografía 13. Letrero que prohíbe extracción de leña, carretera TiculMérida. (Joaquín Quiroz Carranza) 
El crecimiento poblacional aumenta el consumo de leña, la competencia se incrementa y con ello los conflictos sociales derivados de la escasez de material combustible se hacen más agudos. Cuando se pregunta a un usuario de leña por qué la usa, la respuesta es: «porque se encuentra cerca, además el gas es muy caro y el camión repartidor no llega hasta acá» (comunicación personal doña Silvia, Nenelá, Tadhziú, Yucatán, 2009).

Adicionalmente, la argumentación ambientalista, mediatizada y tendenciosamente utilizada por los dueños de los medios masivos de información, minimiza la generación diferenciada de dióxido de carbono, principal gas de efecto invernadero, convenciendo paulatinamente a la sociedad civil y a los tomadores de decisiones de que el crecimiento demográfico, la pobreza y las tecnologías tradicionales son las principales causas del cambio climático, no las grandes industrias de los hidrocarburos, la industria automotriz, el complejo industrialmilitar ni el consumo suntuario de la alta burguesía y las clases medias adineradas.

Al respecto, baste señalar que en 1990 la contribución de la combustión de leña a las emisiones totales de $\mathrm{CO}_{2}$ representó entre el 0.9 y el $2.3 \%$ de las emisiones mundiales (Díaz 2000: 1-5) y en el 2007 no superó el 4\% (Ghilardi et al. 2007: 475-491). Ha de considerarse que toda la combustión y respiración de la biomasa terrestre y marina se encuentra dentro del balance global natural, no así las emisiones derivadas de hidrocarburos (Leggett 1990: 480-501). Desde la revolución industrial (1750) a la fecha, el uso de combustibles derivados de hidrocarburos ha incrementado el $\mathrm{CO}_{2}$ atmosférico de $280 \mathrm{ppm}$ a 386.8 ppm (Organización Meteorológica Mundial 2010: 1-4), concentración que pudiera incrementarse a los $500 \pm 50$ ppm (Stern 2007: 1-32), demarcación considerada como el límite superior a partir del cual los cambios climáticos globales serían incalculables y desastrosos para la civilización humana y para la permanencia del Homo sapiens como especie dominante.

De acuerdo con INE-Semarnat (2009: 1-10), en 1990 México contribuyó con el 2\% de las emisiones globales de $\mathrm{CO}_{2}$ cuya distribución por sectores fue de la siguiente manera: sector 
industrial, 41.6\%; agricultura, ganadería y silvicultura, 30.5\%; transporte, 21.3\%; residencial, 5.3\%; y otros $1.1 \%$. El $84 \%$ de la energía total final se generó a partir de hidrocarburos y el 16\% por hidroeléctricas, geotermia y biomasa (leña, bagazo y otros).

La leña se obtiene del monte, de la milpa, del solar o traspatio, de parques y jardines públicos. Los leños delgados se trozan a mano, los de mayor grosor se parten usando la coa. Los usuarios tienen una escala de preferencia, así, en primer lugar se colectan las ramas secas desprendidas y, si éstas fueran escasas, se apropian de las ramas secas en pie. Aante la insuficiencia de este material, se cortan las ramas verdes en pie y ocasionalmente árboles completos, siendo esta última una acción esporádica.

Una vez recolectada, cortada y estructurada en atados, la leña se traslada a la vivienda cargada sobre la espalda del colector, en unidades denominadas «rollos», cuyo peso varía entre 6 y $25 \mathrm{~kg}$ según sea un niño, mujer u hombre el recolector. También se usa para su transporte bicicletas, triciclos, burros, carretas y vehículos automotores, de acuerdo a la capacidad económica de la familia (fotografías 14, 15, 16 y 17). De esta forma, se lleva la leña a la vivienda, recorriendo desde algunos cientos de metros hasta cerca de $5 \mathrm{~km}$, dependiendo de la abundancia o escasez de la misma (Soares 2006: 151-175, Quiroz et al. 2009: 20, Quiroz y Orellana 2010: 47-67). 


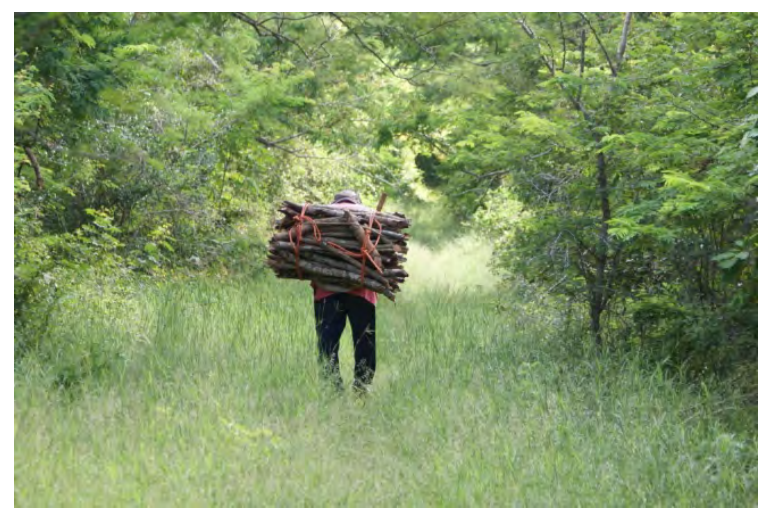

Fotografía 14. Hombre acarreando leña sobre su espalda en Molas, Mérida, Yucatán. (Joaquín Quiroz Carranza)

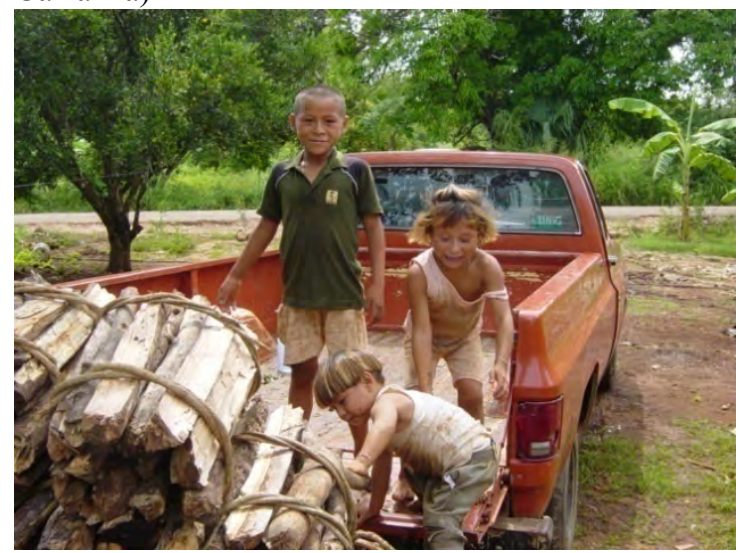

Fotografía 16. Niños ayudando con el acarreo de la leña en Tepakan, Yucatán. (Joaquín Quiroz Carranza)

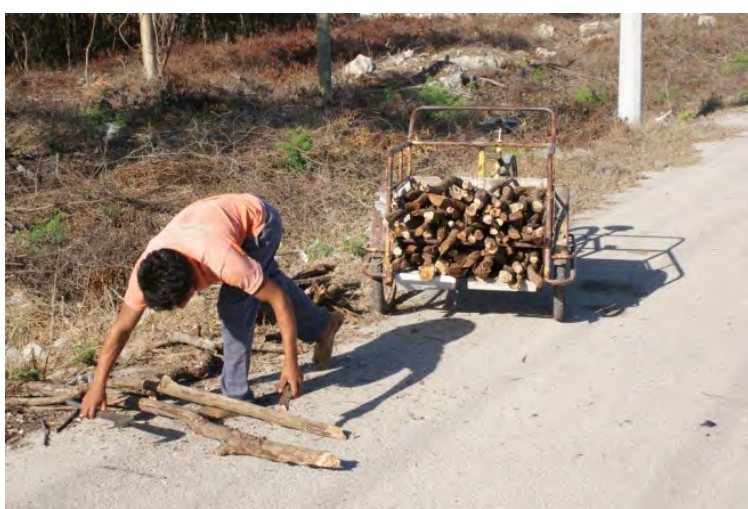

Fotografía 15. Adolescente recolectando leña para transportarla en triciclo en Caucel, Mérida, Yucatán. (Joaquín Quiroz Carranza)

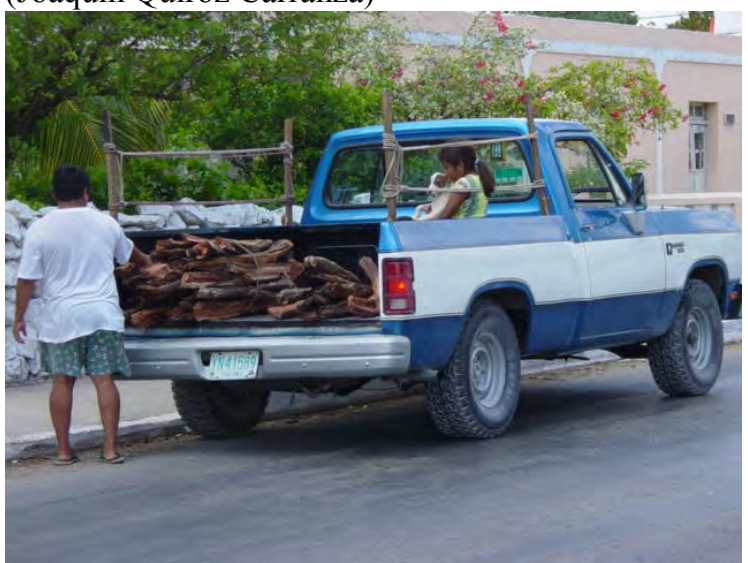

Fotografía 17. Traslado de leña en camioneta en Ucú, Yucatán. (Joaquín Quiroz Carranza)

Cuando la leña se apila en la vivienda, sus habitantes la cuidan y protegen porque de ella depende su bienestar. En la época lluviosa la resguardan para evitar que se humedezca y con esto dificultar su encendido. En la época seca, la leña verde o semiverde se deja secar al aire libre. La mujer rural sabe que existen diversos tipos de leña: algunos sirven para encender el fogón, generalmente son maderas suaves, otras son para alumbrar y mantener el fuego por un largo período, y otras para generar brasas. Por su parte, el hombre reconoce en el monte las especies susceptibles de ser usadas como leña, que no generan humo, son de lenta combustión y producen buen calor.

Las propiedades señaladas les permiten clasificar localmente las especies de buena leña como el tzalam (Lysiloma latisiliquum), el habín (Piscidia piscipula), o el box kaatsim 
(Acacia gaumeri); de madera dura, como el chucum (Havardia albicans) y el tinto (Haematoxylon campechianum); o las especies poco apreciadas o de madera suave, como el chacá (Bursera simaruba).

De esta forma, la leña se clasifica por sus propiedades fisicoquímicas en buena, dura, mala o suave, categorización directamente relacionada con la gravedad específica o densidad de la madera, donde aquella considerada buena o dura posee una alta densidad, mientras aquellas definidas como malas o suaves presentan una baja gravedad específica. Por el lugar de extracción, se considera como leña de monte, milpa, solar y áreas públicas. En festividades locales y para la preparación de algunos alimentos se prefieren aquéllas que aportan olores y sabores agradables, como es el caso del habín (Piscidia piscipula) y el kitimché (Caesalpinia gaumeri) para hornear el muucbipollo, o el x-chachakwaj en pibil o enterrado, o el chucum para el cocimiento de pibil nal (elote pibil o enterrado).

En la región maya-yucateca, 43 especies vegetales pertenecientes a 18 familias botánicas son utilizadas como leña. Las más ampliamente utilizadas son las Fabaceae, con 17 especies, las cuales son muy abundantes, como el tzalam (Lysilo malatisiliquum), el kitimché (Caesal piniagaumeri), el chucum (Havar diaalbicans), el habín (Piscidia piscipula), el sakkaatsim (Mimosa bahamensis); de la familia Polygonaceae, el dzidzilché (Gymnopodium floribundum) es el más usado; y de las Burseraceae, el chacá (Bursera simaruba) (Quiroz y Orellana, 2009: 56). Barajas (1987: 143-148) y Sotomayor (2005: 324) señalan que la gravedad específica o densidad del tzalam y habín es elevada (920 y 904 $\mathrm{kg} / \mathrm{m}^{3}$ respectivamente), parámetro que estima la dureza de la madera, mientras que el chacá tiene una baja densidad $\left(570 \mathrm{~kg} / \mathrm{m}^{3}\right)$ y puede considerase madera suave, descripción física que coincide con lo señalado por los usuarios de leña en la península de Yucatán.

La leña combustible a escala doméstica se utiliza fundamentalmente para la cocción de alimentos, para calentar agua de baño y, en menor cantidad, para la calefacción de la vivienda en la época fría, cuando los habitantes colocan brasas debajo de las hamacas para 
calentarse. La tecnología más usada para la combustión de leña a escala doméstica es el fogón de tres piedras, el cual posee una eficiencia entre 1 y 17\% (GIRA 2004, Parúas et al. 2007: 70-76). Lo anterior representa que se requiere $1.49 \mathrm{~kg}$ de leña para preparar un kilogramo de tortillas (GIRA 2008).

En el proceso de combustión, los usuarios clasifican la leña según su utilidad. Así, para encender el fogón aprovechan el chacá (Bursera simaruba) y el dzidzilché (Gymnopodium floribundum) debido a que su suavidad, y en el caso del chacá a su alto contenido de resina, facilitan su encendido aunque producen una alta emisión de humo; para alumbrar utilizan el sakkaatsim (Mimosa bahamensis) y el habín (Piscidia piscipula); para dar calor, el tinto (Haematoxylon campechianum) y el chakté (Caesalpinia violeacea); y para producir ceniza, el chechén (Metopium brownei) y el tsusuk (Diphysa carthagenensis).

Pero en momentos de escasez se somete a combustión cualquier tipo de leña, sin importar la especie o el grosor, y también se queman en el fogón la cáscara de coco y el bakal (centro de la mazorca u olote), entre otros materiales derivados de biomasa.

El fogón de tres piedras, como su nombre indica, está constituido por tres segmentos de roca dura o laja de aproximadamente $30 \mathrm{~cm}$ x $30 \mathrm{~cm}$ x $30 \mathrm{~cm}$. Según Estrada et al. (2008: 15-17), en Yucatán se han identificado tres capas en el sustrato calizo: laja, saskab y coquina o conchuela. La primera está formada por una capa de roca dura localizada entre $0.3 \mathrm{~m}$ y $2.5 \mathrm{~m}$ de profundidad, denominada localmente como «laja», que puede ser blanca, crema, gris o roja. Este material posee una densidad de $2.6 \mathrm{~g} / \mathrm{cm}^{3}$ y una resistencia mecánica de $2,289 \mathrm{~kg} / \mathrm{cm}^{2}$. Este mineral, por su densidad y resistencia, se utilizó durante la época prehispánica en la construcción de estructuras arquitectónicas mayas, mientras que actualmente se usa para la cimentación de viviendas, la construcción de bardas o albarradas, y para el fogón.

Las piedras de un buen fogón son un artículo cuidado, conservado y heredado entre las 
familias. Las rocas para el fogón se localizan en el monte mediante la observación y la prueba tradicional de dureza, la cual consiste en golpear la piedra con el machete o coa. Si durante esta acción se generan chispas, ello muestra la resistencia o dureza del material. Al respecto, don José (comunicación personal, 2008), residente en la localidad de Kancabchén, señala que «pues hay que buscar piedras duras, que no se revienten con el calor, si no psss se hacen cal. Yo lo que hago es probarlas, le doy así... con el lomo de la coa, si salta lumbre, pues es buena y si se desmorona, pues no sirve».

El fogón de tres piedras ha resistido como parte de la cultura campesina e indígena debido a su bajo costo, ya que no representa ninguna erogación monetaria por parte de los usuarios; es de fácil consecución, uso y control; se puede trasladar fácilmente de lugar; pueden usarse diversos combustibles como son leña, cáscaras de coco, olotes, entre otros; y se adapta a las formas de los recipientes (GIRA 2003:6). En la actualidad se le han incorporado diversas opciones desde lo local pero sin afectar fundamentalmente su estructura y eficiencia energética, la cual es baja.

Desde la sociedad civil organizada y un segmento de científicos comprometidos con el desarrollo endógeno, se han elaborado y fomentado diversas propuestas de fogones mejorados como son la estufa Lorena y la Patsari, desarrollada esta última por el Grupo Interdisciplinario de Tecnología Rural Apropiada (GIRA, AC), y promovida por la Asociación Red Verde, AC. También se ha difundido el modelo tuúmbenk'óoben, impulsado por Uyolchee AC de Quintana Roo, entre otros. Se trata de esfuerzos colectivos con más de 30 años de historia y cuya eficacia puede ser socavada por los programas masivos gubernamentales.

\section{LA TRANSFERENCIA TECNOLÓGICA DESDE EL GOBIERNO}

El gobierno federal a través de las delegaciones estatales de la Secretaría de Desarrollo Social, ha promovido la distribución masiva de fogones eficientes a través del denominado 
Programa Nacional de Estufas Ahorradoras de Leña (PNEAL). Este programa pretende instalar 500,000 fogones en todo el país con una inversión aproximada de mil millones de pesos hasta el 2012.

Pero el PNEAL, como el común de los programas gubernamentales, basados fundamentalmente en buscar y transferir el beneficio económico a los empresarios capitalistas, ha hecho caso omiso de las recomendaciones de los especialistas independientes, las cuales son:

- Difundir solamente estufas cuyo diseño haya sido probado en campo previamente.

- Que sean eficientes, robustas, seguras y durables.

- Desarrollar un programa de sensibilización y capacitación para los usuarios.

- Dar un seguimiento y monitoreo constante para conocer los resultados y evaluar el programa (Rembio 2010).

Hasta el año 2010, el PNEAL ha comprado mediante procesos de licitación más de 100,000 estufas y, de acuerdo con la Rembio (2010), ese mecanismo de adquisición ha fracasado ya desde hace 30 años, tanto en México como en otros países donde se implementaba en gran escala. La licitación obliga a las empresas participantes, según parámetros preestablecidos, a ofertar un artículo con el menor costo y que cubra con características determinadas.

En Yucatán, la delegación estatal de Sedesol promovió durante los años 2009 y 2010, la entrega y colocación de 5,000 fogones del modelo Chiantli, elaborados por la empresa Mexalit Industrial S. A. de C. V. Se dio seguimiento al proceso de entrega de 2,457 fogones en 28 localidades de diez municipios de Yucatán. Se observó que la política gubernamental no busca recuperar la opinión de los beneficiarios ni facilitar su participación creativa, pues en la realidad los usuarios se reconocieron como tales cuando se les entregaba su respectivo fogón (fotografías 18, 19, 20 y 21). Durante el proceso, la actitud oficial fue, como es conocido, de beneficencia, donde los pobres son receptores pasivos. Y, ante cualquier 
intento de adopción y adecuación creativa de la tecnología, se pretendía una rectificación «explicando» el funcionamiento estándar del sistema tecnológico.

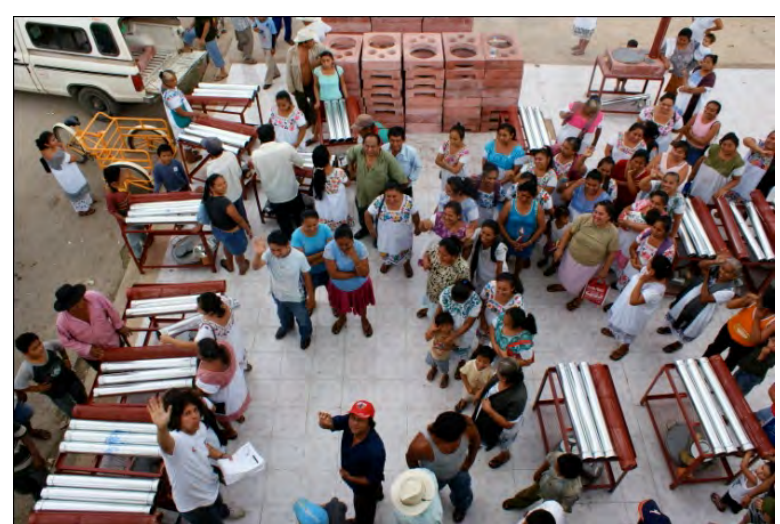

Fotografía 18. Sesión de entrega de fogones en Mayapan, Yucatán. (Pablo Quiroz Cantú)

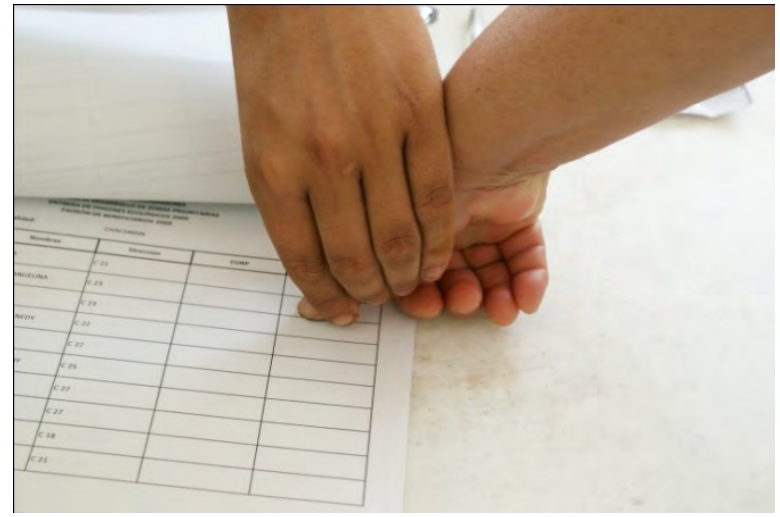

Fotografía 20. Guiando la colocación de la huella digital sobre los formatos oficiales para la entrega de fogones. (Pablo Quiroz Cantú)

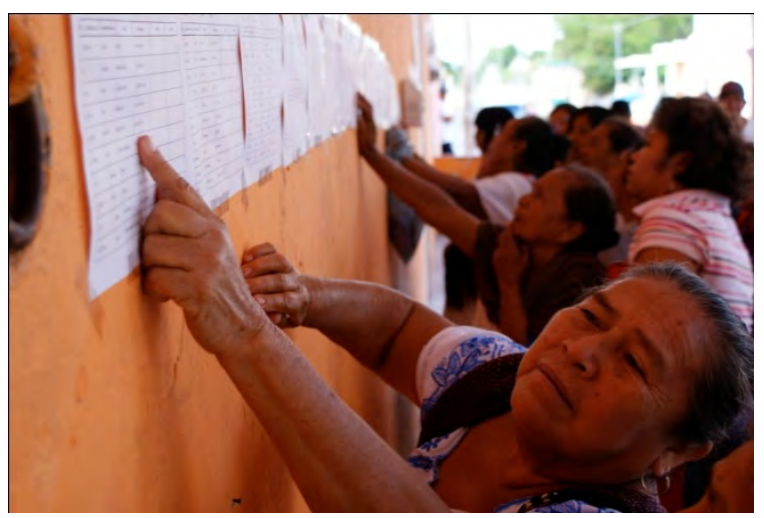

Fotografía 19. Mujeres de Tetíz, Yucatán, corroborando su nombre en las listas de beneficiarios de fogones. (Pablo Quiroz Cantú)

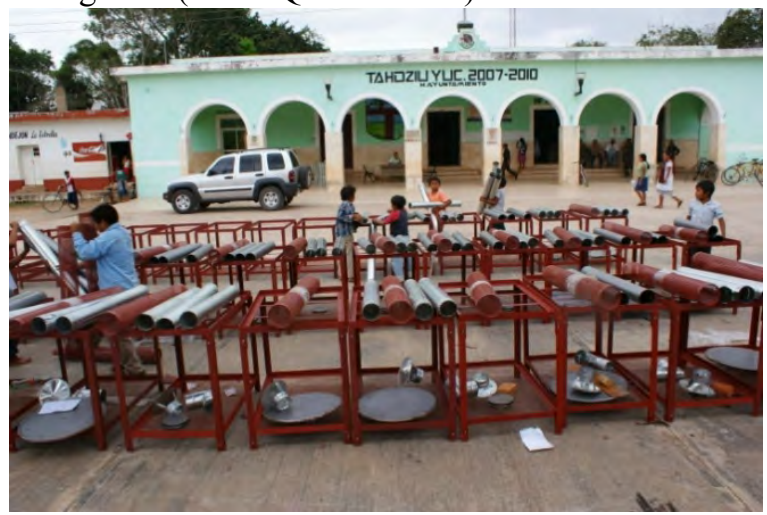

Fotografía 21. Proceso de construcción y entrega de fogones en Tahdziu, Yucatán. (Pablo Quiroz Cantú)

Las observaciones realizadas evidencian que los mecanismos gubernamentales de operación no son adecuados para que cada familia obtenga un dispositivo eficiente, durable, útil y seguro para cocinar sus alimentos, por las siguientes razones:

- No existe un proceso de información a los usuarios sobre su condición de receptores del fogón. En su totalidad se enteraron cuando se publicó la lista de beneficiarios en la localidad. 
- Se obliga a usar el fogón bajo las especificaciones técnicas del fabricante, sin posibilidad de adaptarlo a las condiciones de vida del usuario.

- La presencia de fallas de construcción, ya que las piezas de concreto mostraban grietas y fisuras que permitían el paso de gases y humos derivados de la combustión al encender el fogón.

- Los proveedores de estufas no tienen experiencia en el diseño, elaboración, evaluación ni difusión e implementación de este tipo de tecnologías (Rembio, 2010).

El procedimiento seguido para la entrega de los fogones fue el siguiente:

El fabricante entregaba los fogones en las bodegas de Diconsa, desde donde se trasladaban a las localidades. En cada localidad, la organización de la sociedad civil, seleccionada previamente por la delegación estatal de Sedesol, otorgaba y armaba los fogones en las viviendas de los beneficiarios, previa recepción de la documentación comprobatoria (copia de credencial para votar y CURP) y de su firma o huella digital en los formatos correspondientes. De esta forma, ni el proveedor ni Sedesol se hacen responsables ya que son organizaciones de la sociedad civil las que se encargan del proceso aunque no tienen responsabilidad real sobre el mismo.

Finalmente, y lo más importante, los usuarios no tienen la menor posibilidad de decidir el tipo de estufa que les gusta y que cubra sus necesidades de cocinado. En la mayoría de los casos se les impone un modelo de estufa que no cumple con sus expectativas. No existe acompañamiento para la adopción, ni seguimiento al funcionamiento de la tecnología, y mucho menos monitoreo y evaluación del programa nacional (Rembio, 2010).

La tecnología se entrega a los beneficiarios sin mediar ninguna aportación o participación en el proceso. En la práctica, el objetivo del PNEAL se convierte entonces en instalar o comprar la mayor cantidad de estufas sin importar su funcionamiento, seguridad ni la aceptación del dispositivo. En conclusión, el objetivo fundamental del proceso de 
transferencia de tecnología no mejora significativamente la calidad de vida de las familias rurales ya que, si bien contribuye relativamente a reducir la concentración de gases al interior de la vivienda, eliminar riesgos de enfermedades y reducir gastos y tiempo por uso de leña en fogones abiertos, no facilita la participación y aportación de los usuarios de la leña y el fogón.

\section{CONCLUSIONES}

El fogón abierto de tres piedras tiene una gran importancia económica, histórica y cultural. Las investigaciones recientes observan áreas de oportunidad para mejorar su eficiencia energética y mantener su continuidad tradicional (Díaz et al. 2004: 1-5), pues se reconoce la baja eficiencia del fogón y el peligro de las emisiones de humo para la salud humana, sobre todo de la mujer y los niños.

Los datos y hechos evidencian que el aprovechamiento de la leña combustible a escala doméstica no impacta desfavorablemente sobre las especies vegetales debido a que fundamentalmente se usan ramas secas desprendidas o en pie y, excepcionalmente, ramas verdes o árboles en pie. Adicionalmente es necesario señalar que la mayoría de las especies preferidas como leña pertenecen a la familia Fabaceae y de forma general éstas poseen una alta capacidad de rebrote.

Para lograr nuevas pautas en los procesos de generación, transferencia, apropiación e innovación de tecnologías relacionadas con el fogón doméstico y el uso de leña combustible, se deben proponer y fomentar nuevas relaciones entre instituciones gubernamentales, empresas y organizaciones de la sociedad civil con las comunidades usuarias. Estas relaciones deben respetar la autonomía de los actores locales sobre su territorio, así como generar de forma endógena capacidades y habilidades que permitan a los actores sociales identificar y priorizar sus necesidades, y reconocer el saber tradicional y su capacidad de transformación. Debe tratarse de una interacción equitativa entre ciencia 
«occidental»y conocimiento tradicional que permita un acoplamiento positivo de la cosmovisión de los pueblos indígenas, campesinos y pobres.

Los procesos masivos de transferencia tecnológica, concebidos como «saltos espectaculares» de combate a la pobreza y de reducción de emisiones de $\mathrm{CO}_{2}$ y otros gases de efecto invernadero, mezclados con la ineficiencia burocrática característica de las instituciones públicas, impiden la efectividad de procesos desarrollados por científicos comprometidos con el desarrollo endógeno y por organizaciones de la sociedad civil que han realizado investigación participativa desde hace más de 30 años. 


\section{BIBLIOGRAFÍA}

Barajas Morales, Josefina, 1987, «Wood specific gravity in species from two tropical forest in Mexico», en IAWA Bulletin n. 8(2), pp.143-148.

Berrueta Soriano, Víctor Manuel y Fernando Limón Aguirre, 2008, «Participación campesina para la generación de tecnología alternativa», en Revista Nueva Antropología, Universidad Nacional Autónoma de México v. XXI, n. 68, pp. 113-129.

Damián Huato, Miguel Ángel, Benito Ramírez Valverde, Filemón Parra Inzunza, Juan Alberto Paredes Sánchez, Abel Gil Muñoz, Juan Francisco López Olguín y Artemio Cruz León, 2007, «Tecnología agrícola y territorio: el caso de los productores de maíz de Tlaxcala, México», en Investigaciones Geográficas, Boletín del Instituto de Geografía, n. 63, UNAM, pp. 36-55.

De Montalembert, M.R. y J. Clément, 1983, Disponibilidad de leña en los países en desarrollo, Estudio FAO: Montes. www.fao.org/docrep/X5329s/x5329s00.htm\#Contents [consulta: 10 de noviembre de $2010]$.

Díaz Jiménez, Rodolfo; Víctor Manuel Berrueta Soriano y Omar Raúl Masera Cerutti, 2004, «De la Lorena a la Patsari: proceso de mejoramiento e innovación de tecnología rural», en Memorias de la LatinAmerica Regional Conference, noviembre, Asociación Nacional de Energía Solar, Guanajuato, México, p. 5.

Díaz Jiménez, Rodolfo, 2000, «Consumo de leña en el sector residencial de México, evolución histórica y emisiones de $\mathrm{CO}^{2} »$, Tesis de maestría en ingeniería energética, UNAM, México, p. 113. 
Dutt, Gautam; Jaime Navia y Claudia Sheinbaum, 1989, «Cheranatzícurin, tecnología apropiada para cocinar con leña», en Revista Ciencias, n. 15, Facultad de Ciencias, UNAM, pp. 43-47.

Estrada-Medina, Héctor; Andrés Zanatta; Saúl Valdéz y Sergio Raúl Casolco, 2008, «Evaluación de las propiedades mecánicas de las rocas calizas de Yucatán: su importancia en el crecimiento radicular», en Journal de Investigación de la Escuela de Graduados e Innovación Instituto Tecnológico de Monterrey Campus Puebla, pp. 15-17.

Fuentes Amour, Judith, 2009, «Relación entre tecnología, conocimiento y culturas locales», en Ide@s CONCYTEG, año 4, n. 45, 9 de marzo, pp.346-361..

Ghilardi Álvarez, Adrian, Gabriela Guerrero y Omar Raúl Masera Cerutt, 2007, «Spatial analysis of residential fuelwood supply and demand patterns in Mexico using the WISDOM approach», en Biomass and Bioenergy, v. 31, pp. 475-491.

Grupo Interdisciplinario de Tecnología Rural Apropiada, (GIRA) 2008, «Energy performance of wood-burning cookstoves in Michoacan, Mexico», en Berrueta V., Rufus E. and $\mathrm{O}$. Masera, Renewable Energy, en .www.gira.org.mx/index.php?option=com_content\&task=view\&id=75\&Itemid=71 [consulta 11 de noviembre de 2009].

_ _ 2004, «Informe final. El uso de estufas mejoradas de leña en los hogares: evaluación de reducciones en la exposición personal», en www.ine.gob.mx/descargas/calaire/informe_estufas_piloto_mz_lrb_final.pdf [consulta: 11 de abril de 2005).

—_, 2003, «El uso de biomasa como fuente de energía en los hogares: efectos en el ambiente y la salud, y posibles soluciones», p. 6 . 
Guzmán Urióstegui, Jesús, 2007, «Entre el fogón y la milpa. El espacio entre los mayas de Xohuayán, Yucatán», en Dimensión Antropológica, año 14, v. 39, pp. 101-120.

Hirose López, Javier, 2007, «El cuerpo y la persona en el espacio-tiempo de los mayas de los Chenes, Campeche», en Revista Pueblos y Fronteras digital, Universidad Nacional Autónoma de México, n. 4, diciembre 2007 - mayo 2008, pp.1-31.

Instituto Nacional Estadística Geografía e Informática (Inegi), 2000, «Sistema para la consulta de la información censal (SINCE)». México. Disco compacto.

Instituto Nacional de Ecología, Secretaria de Medio Ambiente y Recursos Naturales, 2009, «Inventario nacional de emisiones de gases de efecto invernadero con cifras de 1990», Dirección de Cambio Climático y Dirección General de Regulación Ambiental, Semarnat, México, pp. 1-10.

Leggett, Jeremy, 1990, «El calentamiento global: el punto de vista de Greenpeace», en El calentamiento global, informe de Greenpeace, compilado por Leggett, Jeremy, Fondo de Cultura Económica, México, pp. 480-501.

Long Towel, Janet, 2008, «Tecnología alimentaria prehispánica», en Estudios de Cultura Nahuatl, v. 39, Instituto de Investigaciones Históricas, UNAM, México, pp. 127-136.

Manjarrez, Silvia y Andión Montaño, 2010, Crónicas de la mujer en el milenario Anáhuac, Miguel Ángel Porrúa, México, p. 246.

Martínez Alier, Joan, 1991, «La pobreza como causa de la degradación ambiental. Un comentario al Informe Brundtland», en Documents D’ Análist Geográfica n. 1, pp. 55-73. 
Masera Cerutti, Omar Raúl y Alfredo F. Fuentes Gutiérrez, 2006, «Introducción», en La bioenergía en México, un catalizador del desarrollo sustentable, coordinado por Macera Cerutti, Omar, Mundi Prensa, México, pp. 1-6.

Oliver, Beatriz; Beatriz Moreno y Susana Muñoz, 2003, «Cambios y tradiciones. Estructura comunitaria y transformaciones sociales en el Valle del Mezquital», en La comunidad sin límites, estructura social y organización comunitaria en las regiones indígenas de México, coordinado por Millán, Saúl y Julieta Valle, Instituto Nacional de Antropología e Historia, México, pp. 103-142.

Organización Meteorológica Mundial, 2010, «Estado de los gases de efecto invernadero en la atmósfera según observaciones mundiales realizadas en 2009», en Boletín sobre gases de efecto invernadero, n. 6, pp. 1-4.

Parúas Cuza, Rafael, Osvaldo Núñez Bosch, Ángel Almarales Arceo, Gretchen Torres Céspedes y Teresita Arias Chalico, 2007, «Algunas consideraciones sobre el uso eficiente de la leña para la cocción de alimentos en el sector doméstico en la provincia de Guantánamo», en Tecnología Química, v. XXVII, n. 1, pp. 70-76.

Quiroz Carranza, Joaquín y Roger Orellana Lanza, 2010, «Uso y manejo de leña combustible en viviendas de seis localidades de Yucatán, México», en Revista Madera y Bosques, v. 16(2), Instituto de Ecología, México, pp. 47-67.

Quiroz Carranza, Joaquín; Citlalli Cantú Gutiérrez; Rodolfo Díaz Jiménez y Roger Orellana Lanza, 2009, Uso de la leña en Yucatán y tecnología para su aprovechamiento sustentable, Asociación Red Verde, Centro de Investigación Científica de Yucatán, Mérida, p. 74.

Red Mexicana de Bioenergía (Rembio), 2010, Pronunciamiento Rembio sobre el programa de estufas de leña de la Sedesol, en http://tuumbenkooben.wordpress.com [consulta: 2 de 
agosto de 2010].

Samir, Amin, 1977, «La transferencia de tecnología: una crítica», en Nueva Sociedad, n.. 31-32, julio-octubre, pp. 198-205.

Secretaría de Medio Ambiente y Recursos Naturales, 2008, Transferencia de tecnología y divulgación sobre técnicas para el desarrollo humano y forestal sustentable. Estufa ahorradora de leña, Comisión Nacional Forestal, México, p. 22.

Soares, Denise, 2006, «Género, leña y sostenibilidad: el caso de una comunidad de los Altos de Chiapas», en Economía, Sociedad y Territorio, v. VI. n. 21, México, pp. 151-175.

Sotomayor Castellanos José Ramón, 2005, «Características mecánicas y clasificación de la madera de 150 especies mexicanas», en Investigación e ingeniería de la Madera, n. 1(1), Universidad Michoacana de San Nicolás, México, pp 3-24.

Stern, Nicholas, 2007, Stern Review: la economía del cambio climático, HM Trasury, Reino Unido, pp. 1-32.

Tapia Naranjo, Alfredo, 2002, «El proceso de investigación y transferencia de tecnología en el sector agricultura», en La experiencia del INIFAP. Aportes, mayo-agosto v. VII, n. 20, Benemérita Universidad Autónoma de Puebla, México, pp. 179-183.

Troncoso, Karin, Alicia Castillo, Omar Masera y Leticia Merino, 2007, «Social perceptions about a technological innovation for fuelwood cooking: Case study in rural Mexico», en Energy Policy, n. 35, pp. 2799-2810.

Zibechi, Raúl, 2010, Contrainsurgencia y miseria. Las políticas de combate a la pobreza en América Latina», Editorial Pez en el Árbol, México, p. 205. 
Fecha de recepción: 23 de febrero de 2011.

Fecha de aceptación: 15 de agosto de 2011. 